\title{
Crystal growth of Li salts from aqueous solutions and gels studied by Raman spectroscopy
}

\author{
F. RULL, M. PRIETO* and F. SOBRON** \\ Dpto. de Cristalografía y Mineralogía, Facultad de Ciencias, Prado de la Magdalena s/n, 47005 Valladolid, \\ Spain \\ ${ }^{*}$ Dpto. de Geología, Facultad de Geológicas, Arias de Velasco s/n, 33005 Oviedo, Spain \\ ** Dpto. de Ingeniería Química, Facultad de Ciencias, Prado de la Magdalena s/n, 47005 Valladolid, \\ Spain
}

\section{ABSTRACT :}

A Raman spectroscopic study of aqueous solutions of $\mathrm{Li}_{2} \mathrm{SO}_{4}, \mathrm{LiNaSO}_{4}$ and $\mathrm{LiKSO}_{4}$ as function of concentration and temperature has been performed. From a band profile analysis of the internal modes of the sulphate ion, the spectroscopic association constant has been calculated at different temperatures.

It has been also possible to measure the diffusivity coefficients for $\mathrm{Li}_{2} \mathrm{SO}_{4}$ in bulk solutions and in gels, using Raman spectroscopy.

These data are used in the interpretation of the crystallization behaviour of $\mathrm{Li}$ salts from aqueous solutions and gels.

\section{INTRODUCTION}

The precise knowledge of the chemical processes occurring in the aqueous media and the mass transfer of fluids are very important stages in the understanding of the crystal growth from aqueous solutions. Although many of the available data on the properties of aqueous solutions of electrolytes come from macroscopic sources, data obtained from microscopic sources (mainly diffraction and vibrational spectroscopy) allow in some cases to introduce new insights on the understanding of these phenomena.

Of particular importance are the IR and Raman spectroscopy from which valuable information at molecular level can be obtained.

The main aims of our work is the study of the crystallization behaviour of Li salts with applications as ionic conductor and piezoelectric materials from bulk aqueous solutions and gels. Particular interest is devoted to Lithium sulphate and the double salts $\mathrm{LiKSO}_{4}$ and $\mathrm{LiNaSO}_{4}$. In the case of $\mathrm{Li}_{2} \mathrm{SO}_{4}$, crystals have been obtained using different methods (melting, hydrothermal or water/sulfuric acid solvents) [1]. Starting from the melt it is not possible to obtain high quality single crystals in the monoclinic phase because the large discontinous volume change at the cubic-monoclinic transition which provokes a great number of cracks in the crystals. Within this general framework, one of our goals is the growth of these salts at low temperatures. For this we use mixture solvents, mainly methanol/water and ethanol/water mixtures. sulphates.

In the present work we report some data on the following steps of the crystallization process of Li-

1. The study of the growth media by a) the phase diagrams and macroscopic properties at differents temperatures of the systems $\mathrm{Li}_{2} \mathrm{SO}_{4} \quad \mathrm{Li}_{2} \mathrm{SO}_{4}-\mathrm{Na}_{2} \mathrm{SO}_{4}$ and $\mathrm{Li}_{2} \mathrm{SO}_{4}-\mathrm{K}_{2} \mathrm{SO}_{4}$ in water and in mixed methanol/water solvents and b) a structural study of these systems at different concentrations and temperatures by means of Raman and IR spectroscopy.

2. The study of the mass transport of the reactants in aqueous solutions and in gels by means of the Raman spectroscopy.

A crucial point in these items is the connection between the data obtained at molecular level and the macroscopic properties. We will focus the attention in this paper on the discussion on the relation between 
the spectroscopic results and the macroscopic data. To achieve this, some parameters with macroscopic (thermodynamic) significance should be obtained from the spectra. Among these, association parameters ( $\mathrm{K}_{\mathrm{ass}}, \Delta \mathrm{H}$ and $\Delta \mathrm{S}$ ) and mass transport parameters (relaxation times and diffusivity coefficients) are, in our opinion, of particular importance.

\section{EXPERIMENTAL}

Details on the experimental set-up for phase diagrams and macroscopic properties measurements can be found in [2]. The Raman spectra of aqueous solutions were taken in a Ramanor HG2S double monochromator and in a SPEX spectrophotometer both coupled to a computer and in the usual $90^{\circ}$ scattering configuration.

As excitation the $514.5 \mathrm{~nm}$ and the $488.0 \mathrm{~nm}$ lines of an argon ion laser were used. The incident power at the sample was about $300 \mathrm{~mW}$. Spectra at different temperatures in the range 50 to $80^{\circ} \mathrm{C}$ were obtained on samples with different concentrations thermostated to $\pm 0.1^{\circ} \mathrm{C}$ in fused silica cells using a circulating water bath.

In the case of the spectroscopic mass transport measurements, experimental arrangements were specially constructed based on diffusion phenomena along glass tubes with very large length/diameter ratios (a capillary of $25 \mu$ internal diameter and $20 \mathrm{~cm}$ length and a vertical tube of $3 \mathrm{~mm}$ internal diameter and 60 $\mathrm{cm}$ length). Finally, the transport in gel was monitored by using vertical tubes of $8 \mathrm{~mm}$ internal diameter and $12 \mathrm{~cm}$ length. In these tubes the silica gel occupies about $3 / 4$ of the total and in the remain volume at the top are placed the different liquid systems.

Because of the presence of fluorescence under 514.5 and $488.0 \mathrm{~nm}$ exciting lines a FT-Raman spectrometer with laser excitation in the IR region $(1100 \mathrm{~nm})$ was in this case used.

\section{RESULTS AND DISCUSSION}

\subsection{Association processes}

Although there are some limitations in sensitivity at low concentrations, Raman spectroscopy is a powerful tool for examine the nature of ion association in aqueous electrolyte solutions when the solute contains polyatomic ions. In the case of sulphates the profile modification of the $v_{1}\left(\mathrm{SO}_{4}\right)$ symmetric stretching band has been taken for some authors as an evidence of the ion association [3]

For $\mathrm{Li}_{2} \mathrm{SO}_{4}$ the modification consist in an asymmetry in the high wavenumber side of the band which appears as a shoulder when concentration and temperature increases.

The estimation of the band parameters of this shoulder is dependent on some subjective criteria when curve resolving programs are used. In order to overcome this limitation we have developed a general method of self-deconvolution band profile using Fourier transform analysis. [4]. The advantage of this method is that it allow the estimation of the number and band parameters of the possible components contained under a complex band profile without any previous assumption about them. The data thus obtained are used as input in a curve-fitting program which allow the optimisation of the band parameters by means of least-squares routines. Figure 1 illustrates the method for a saturated $\mathrm{Li}_{2} \mathrm{SO}_{4}$ solution at room temperature .

If we assume the component $B_{1}$ at $982 \mathrm{~cm}^{-1}$ correspond to the sulphate ions non participating in ionic association with Lithium ions and the $989 \mathrm{~cm}^{-1}$ component $\mathrm{B}_{2}$ correspond to the associates sulphates and we assume the same molar scattering coefficient for the two species of sulphate we can calculate the association constant for the reaction

$$
2 \mathrm{Li}^{+}(\mathrm{aq})+\mathrm{SO}_{4}^{2-}(\mathrm{aq}) \rightleftharpoons \mathrm{LiSO}_{4}^{-}(\mathrm{aq})+\mathrm{Li}^{+}(\mathrm{aq})
$$




$$
\text { Kass }=\frac{1-\alpha}{\alpha(\alpha+1) \mathrm{m}} \frac{\gamma_{\mathrm{t11}}^{2}}{\gamma_{\mathrm{t12}}^{3}} \approx Q_{\cdot} \cdot Q_{\gamma}
$$

where $\alpha=I_{982} / I_{\text {tot }}, 1-\alpha=I_{989} / I_{\text {tot }}, m$ is the molality and $Q_{\gamma}$ is assumed to be $\left(1 / \gamma_{ \pm 12}\right)^{2}$ [5]. The data for $\gamma_{ \pm 12}$ were taken from Holmes and Mesmer [6]. In the range 0.5 to $2.5 \mathrm{~m}$ where the activity coefficient is practically constant $Q_{c}$ is found to be also constant. The average values of $Q_{c}$ and $K_{a s s}$ ( $s p$ ) in these interval are respectively $0.09 \mathrm{~kg} \mathrm{~mol}^{-1}$ (standard error 0.004 ) and 1.24 (standard error 0.041 ). This last value is lower than the one obtained from macroscopic measurements $\mathrm{K}_{\mathrm{ass}}=5$ [7].

This difference is interpreted on the basis the $\mathrm{Li}_{-} \mathrm{SO}_{4}$ association is a multistage process. The macroscopic measurements will reflect all interactions taking place in the solution (from short to long range distances ) but the Raman spectra only those acting over short range distances. The long distance interactions can be calculated on the basis of electrostatic forces using the Bjerrum equation [8]. The summation of the value thus calculated and the spectroscopic one is in a good agreement with the macroscopic obtained value.

The dependence of the spectroscopically obtained $\ln \mathrm{K}_{\mathrm{ass}}(\mathrm{sp})$ with $1 / \mathrm{T}$ is presented in Figure 2 . The points can be fitted by a straight line (regression coefficient 0.97 ). From this plot the enthalpy and entropy for the association were calculated $\Delta \mathrm{H}=20 \mathrm{KJ} / \mathrm{mol}, \Delta \mathrm{S}=70 \mathrm{~J} / \mathrm{mol} \mathrm{K}$.

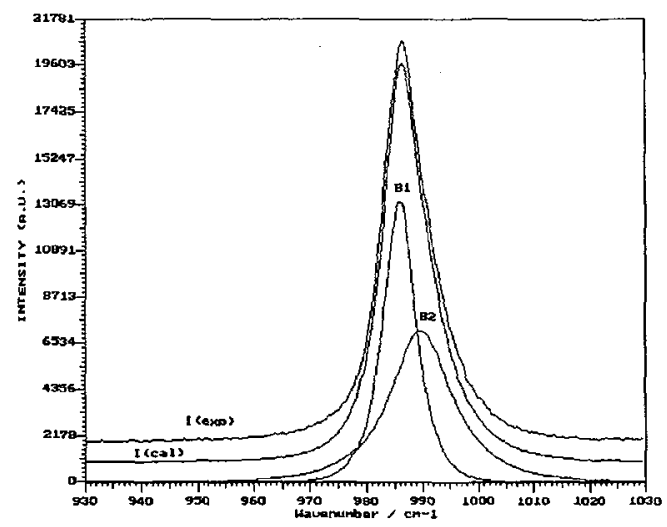

Figure 1

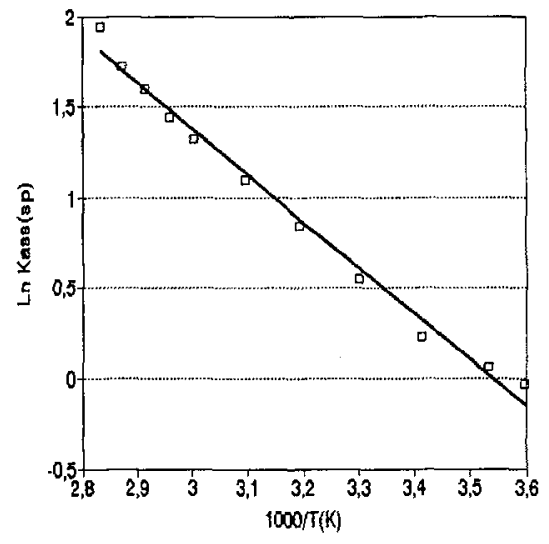

Figure 2

\subsection{Transport properties}

Figure 3 shows the evolution of the integrated intensity of the Raman spectra of $v_{1}\left(\mathrm{SO}_{4}\right)$ in a $2 \mathrm{~m}$ $\mathrm{Li}_{2} \mathrm{SO}_{4}$ aqueous solution diffusing along the closed vertical tube for times up to 25 days and the axial profile at this time. Together with these results are shown the computer simulation of the process where $\mathrm{C} / \mathrm{C}_{\mathrm{O}}$ is the concentration quotient obtained from the measured intensity ratio at different positions of the tube to the position $\mathrm{L}=0$ ( which is taken in our case $2 \mathrm{~cm}$ apart from the reservoir).

From these data, the time evolution is fitted by a $\mathrm{D}_{\mathrm{a}}$ value ranging between $0.43 \times 10^{-5}$ and 0.45 $\times 10^{-5} \mathrm{~cm}^{2} / \mathrm{s}$ and the axial profile by a value of $0.37 \times 10^{-5} \mathrm{~cm}^{2} / \mathrm{s}$. The data obtained from the capillary can not to be fitted by the same $D_{a}$ value except if a convective flow rate of about $5 \times 10^{-2} \mathrm{~cm} /$ hour is introduced in the model. We assume in consequence $\mathrm{a} \mathrm{D}_{\mathrm{a}}$ value of $0.41 \times 10^{-5} \mathrm{~cm}^{2} / \mathrm{s}_{\text {for }} \mathrm{Li}_{2} \mathrm{SO}_{4}$ in aqueous solution ( at 2 $\mathrm{m}$ concentration) which is found to be in good agreement with the values obtained for other sulphates ( $\mathrm{MgSO}_{4}: 0.39 \times 10^{-5} \mathrm{~cm}^{2} / \mathrm{s} ; \mathrm{CuSO}_{4}: 0.58 \times 10^{-5} \mathrm{~cm}^{2} / \mathrm{s}$ ) from macroscopic measurements [9]. 
In Figure 4 we present the evolution of the integrated area of the $v_{1}\left(\mathrm{SO}_{4}\right)$ band for a $1 \mathrm{~m} \mathrm{Li} 2 \mathrm{SO}_{4}$ aqueous solutions diffusing along the gel tube, and in Figure 5 we show the results of the computer simulation of process. Because the aqueous solution reservoir can not to be assumed as infinite and there is some water in the gel, the model become rather complicated but the experimental data can be fitted with an acceptable accuracy by a diffusivity coefficient $0.3 \times 10^{-5} \mathrm{~cm}^{2} / \mathrm{s}$ which is not far from the obtained in bulk solutions. That mean the diffusion properties in gels do not differ appreciably from those in bulk solutions.

The differences in transport properties from gel and bulk solution arise from the fact that in the gel, convection is strongly suppressed.

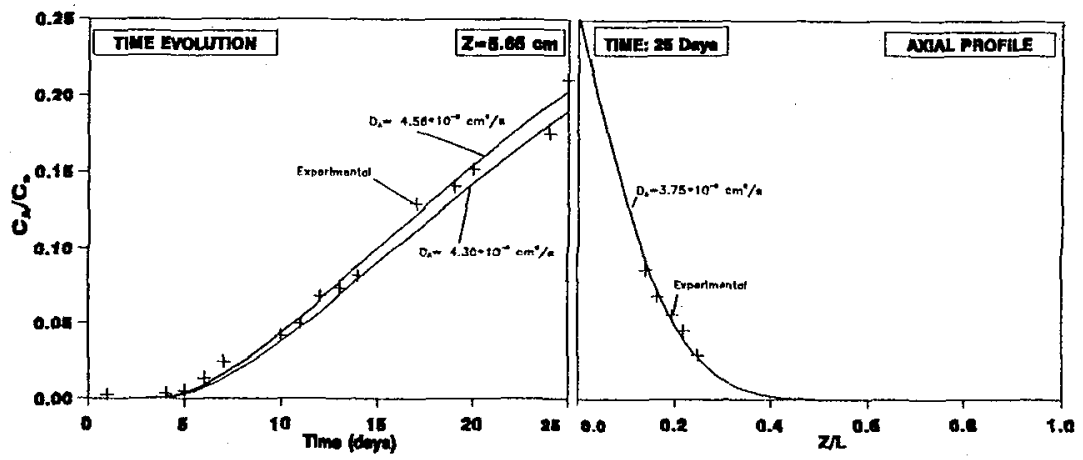

Figure 3

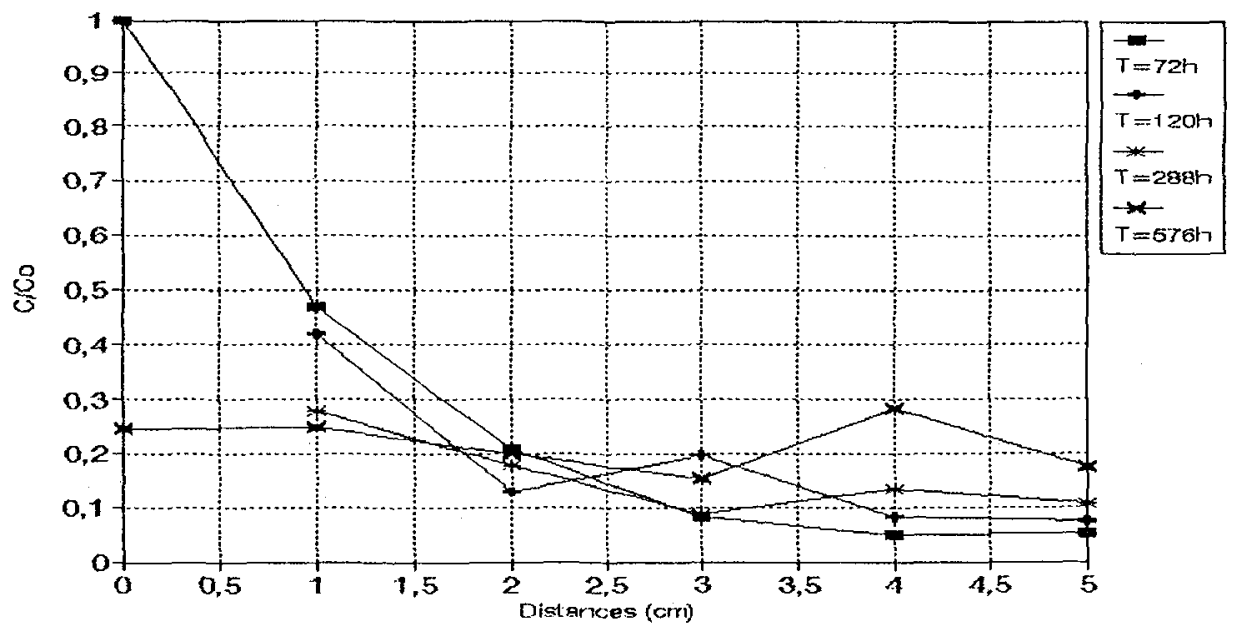

Figure 4 


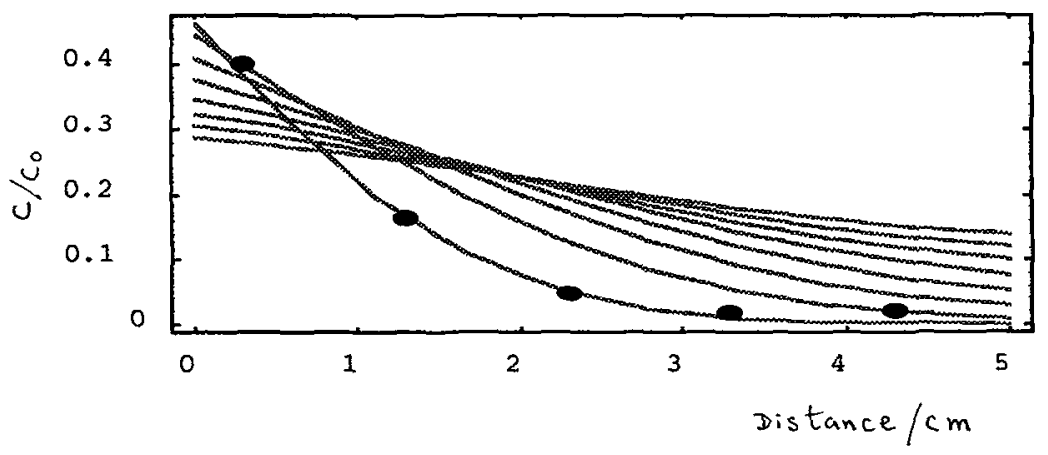

Figure 5

\section{CONCLUSIONS}

Raman Spectroscopy provide a method which complements the clasical macroscopic methods in the characterisation of the growth media. Some times the Raman spectra contains unique data which will lead to a deeper understanding of the thermodynamic properties of the system.

The use of self-deconvolution band profile methods allow the estimation of the Raman band parameters without any previous assumption about these. The data thus obtained can be related in a more objective way with the species presents, their populations and the chemical process taking place. From these the ionic association and their dependence with concentration and temperature has been calculated. It has been also possible to measure (for the first time in our knowledge) the diffusivity coefficients of $\mathrm{Li}_{2} \mathrm{SO}_{4}$ in bulk aqueous solutions and in gels using Raman spectroscopy.

\section{ACKNOWLEDGEMENTS}

The present work is carried out under the support of the Spanish PLANICYT Project MAT 90 /775/ C 03.01.02.03

\section{REFERENCES}

1.- French R., and Cazzanelli E, Solid State Ionics, 9, (1983), 95-100.

2.- Rull F., Prieto M. and Sobron. F., Procc.III Reunión Nacional de Crecimiento Cristalino, Granada 19-21/September/1993.

3.- A. Rodriguez A., F. Sobron F., Rull F., Prieto A.C. and Edwards H.G.M., Sent to Appl. Spectroscopy

4.- Davis A.R. and Oliver B.G., J. Phys. Chem. 77, (1973), 1315-1320.

5.- Rull F., Jiménez J., Sobrón F., Rodriguez A, Electronic and Optoelectronic Materials for the 21th. Century Procc. of the 7th. Internacional School on Condensed Mather Physics, Ed. J. Marshall, N. Kirov, A. Vavrek, World Scientific., (1993), 228-246

6.- Masterton W. L., and Berka L. H., J. Phys. Chem. 70, (1966), 1924-1929.

7.- Holmes H. F. and Mesmer R. E., J. Sol. Chem., 15 (1986), 495-506

8.- Robinson R.A. and Stokes R.H. Electrolyte Solutions Butteworths Sci. Pub. London 1955

9.- Wilcox W. R., "The role of mass transfer in crystallization processes". In preparation and Properties of Solid State Materials. Vol. 1 Ed. by Lefever R. A. (Marcel Dekker, New York, 1971) 